\title{
The Development and Operational Testing of an Underwater Bait Setting System to Prevent the Mortality of Albatrosses and Petrels in Pelagic Longline Fisheries
}

\author{
Graham Robertson 1*, Phillip Ashworth2', Peter Ashworth², Ian Carlyle², Steven G. Candy ${ }^{1}$ \\ ${ }^{1}$ Australian Antarctic Division, Kingston, Australia \\ ${ }^{2}$ Amerro Engineering, Warana, Australia \\ Email: "'graham.robertson1141@gmail.com
}

Received 29 August 2014; revised 13 October 2014; accepted 4 November 2014

Copyright (C) 2015 by authors and Scientific Research Publishing Inc.

This work is licensed under the Creative Commons Attribution International License (CC BY). http://creativecommons.org/licenses/by/4.0/

(c) (i) Open Access

\begin{abstract}
Longline fisheries for tunas and tuna-like species present an existential threat to many populations of albatrosses and petrels worldwide. To prevent this form of mortality we developed a new technology designed to deploy baited hooks underwater beyond the dive depths of seabirds (6 - 10 $\mathrm{m}$ for the species most commonly caught). The underwater bait setter is a stern-mounted, hydraulically-operated and computer-controlled device that catapults baited hooks underwater in a steel capsule connected to hydraulic winches by Spectra ${ }^{\circledR}$ rope. Baits are flushed from the capsule by water pressure through a spring-loaded bait release door. The chief engineering challenges in the developmental stages were ensuring: 1) bait delivery to target depths with cycle times (time from release to recovery) that were practical for fishing operations; 2) bait retention in the capsule (no drop-outs) on the descent phase of the cycle; 3 ) baits, upon release at target depth, were not drawn up the water column on the capsule recovery phase (from possible hook-ups and/or suction); and 4) the retention of baits on hooks post-release from the capsule was not affected by the mechanical release underwater. Operational trials with the final version of the capsule yielded satisfactory cycle times to depths of $6-10 \mathrm{~m}$. All baits were retained in the capsule on the descent and released as required at target depths $(n=606$ deployments). Bait retention on hooks post release from the capsule and retention on hooks hand-set at the surface (the conventional method) were statistically indistinguishable. The underwater bait setter is modular in construction and can be fitted to all types of vessel sterns.
\end{abstract}

\section{Keywords}

Seabird Bycatch, Longline Fisheries, Underwater Setting, Marine Engineering, Innovation,

"Corresponding author.

How to cite this paper: Robertson, G., et al. (2015) The Development and Operational Testing of an Underwater Bait Setting System to Prevent the Mortality of Albatrosses and Petrels in Pelagic Longline Fisheries. Open Journal of Marine Science, 5, 1-12. http://dx.doi.org/10.4236/ojms.2015.51001 


\section{Co-Operative Research}

\section{Introduction}

Longline fisheries are a major threat to the existence of many albatross and petrel populations worldwide. In the most recent global assessment of mortality levels [1] it was estimated that between 160,000 and 360,000 seabirds perish annually in longline fisheries. Seabirds are attracted to fishing vessels by discarded fish waste and baited hooks during line setting operations. Gear is set onto the sea surface where baits are highly visible to seabirds. Seabirds seize baits at the surface or dive on them as they sink, become hooked or ensnared in gear and drown. The species most affected are the albatrosses and petrels with 18 of the worlds' 22 species of albatross species threatened with extinction, principally due to mortality in fisheries [2]. This type of mortality has driven the declines of albatross and petrel populations over decadal time scales at some breeding sites [3] [4] and is the reason for the IUCNs recent (2013) up-listing of the grey-headed albatross (Thalassarche chrysostoma) to "endangered" conservation status [5].

Measures to mitigate seabird mortality in commercial longline fisheries are promoted by international bodies such as the UN's Food and Agricultural Organisation [6] and the Agreement on the Conservation of Albatrosses and Petrels (ACAP; http://www.acap.aq/). The primary measures for tuna and swordfish fisheries are the setting of longlines at night when most seabird species are less active, deployment of streamer lines to scare seabirds from sinking baits and adding weights to branch lines to expedite sink rates. These three measures must be used in concert to be fully effective in deterring seabirds [7]-[9]. Other management options include prohibition on the day setting of longlines (in fisheries where day setting is permitted; [10]) and seasonal and/or spatial closures of fishing grounds [8]. These options are usually recommended if the primary measures fail to attain prescribed seabird conservation targets. An alternative to setting baited hooks at the surface is to set them underwater. Setting baited hooks beneath seabird dive depths has the potential to eliminate seabird mortality completely. There could also be benefits to the fishing industry. Underwater setting could eliminate bait loss to seabirds and enable lines to be set at any time of the day/night cycle without other mitigation, which would simplify operations. Underwater setting could remove the need for area and seasonal closures and the negative consequences of these practises on the economics of fishing.

This paper describes the development and operational testing of an underwater bait setting device for pelagic longline fisheries. The main focus is on the engineering challenges associated with the reliable deployment of baited hooks to pre-determined depths underwater in the propeller turbulence zone of moving fishing vessels, and ensuring bait retention on hooks was not affected by the mechanical release underwater. Effectiveness in preventing seabird by-catch without affecting fish catch will be addressed in a later paper.

\section{Description of Underwater Bait Setter}

The underwater bait setter (hereafter called the UW setter) is a stern-mounted, hydraulically-operated, computercontrolled device that deploys baited hooks individually in a steel capsule beneath the dive depths of albatrosses and petrels. The idea to set baited hooks underwater to prevent seabird mortality originated from members of the fishing industries in New Zealand and Australia (see Acknowledgements). However, the early versions of the machine were rudimentary in design and unreliable to operate. The concept was passed on to (and adopted by) Amerro Engineering, Australia (www.amerro.com.au), who designed and built the UW setter from the ground up. The machine is modular in design to fit all configurations of vessel sterns and comprises the following main components:

\subsection{Winch Assembly}

The winch assembly is the main drive unit of the UW setter. It contains two hydraulic motors-the pull-down motor and the recovery motor-each connected to a winch (pulley). The motors are equipped with hydraulic brakes and encoders. The winches are fitted with Spectra ${ }^{\circledR}$ rope $-8 \mathrm{~mm}$ (breakload: $3000 \mathrm{~kg}$ ) for the pull down motor and $6 \mathrm{~mm}$ (1600 kg) for the recovery motor. The assembly also contains hydraulic solenoids and systems control box with programmable logical controller (PLC). The encoders interface with the PLC to control the 
performance of the UW setter.

\subsection{Track Assembly}

The track assembly comprises two sections-a stainless steel track fitted to the vessel transom to $1.5 \mathrm{~m}$ underwater, and the head unit of the track. The extension to no more than $1.5 \mathrm{~m}$ underwater minimizes drag and vessel fuel consumption. The track is V-shaped in cross section to add strength and reduce water resistance, and is fitted with guide rails on each side for the capsule docking unit (see below). A water operated cushioning piston is fitted to the bottom of the track. The head section connects to the top of the track at the vessel gunnel. Ball races in the head section guide the Spectra from hydraulic motors in the winch assembly to the capsule and the capsule docking unit. The head section also contains a magnetically operated capsule deployment switch. When in the bait loading (home) position the capsule is suspended in the head section about chest height for a crew member to facilitate bait loading. The head section pivots forward and can be stored inboard during transit to and from fishing grounds.

\subsection{Bait Capsule and Capsule Docking Cart}

The bait holding capsule is a stainless steel cylinder measuring $54 \mathrm{~cm} \times 16 \mathrm{~cm}$ and weighs $18 \mathrm{~kg}$. A centre plate divides the capsule into two identical halves. Each side has a bait loading window with a spring loaded flap to prevent bait drop-outs. The base of the capsule is a saucer-shaped spring loaded trap door through which baited hooks are released at target depth. The head section of the capsule is conical and flattened on two sides to facilitate docking with the docking cart. The head section is weighted with lead to enable the capsule to flip upside down on water entry (see below). Sinking upside down prevents the capsule from spinning on its axis and prevents the Spectra and branch line from tangling. Slots in both sides of the outer case allow the branch line to be available for connection to the mainline after firing.

The capsule travels up and down the track in a docking cart. The docking cart is made from high-performance polyethylene (HPPE), which has exceptionally high impact strength, and stainless steel. The various components are cushioned with sleeves of urethane (ethyl carbamate). The docking cart comprises a head section that docks with the capsule and chassis section with water-lubricated wheels that fit to the guide rails of the track. The docking cart is connected to the pull-down hydraulic motor with Spectra which attaches to the cart via a waterlubricated pulley at the base of the track. The rope from the recovery motor connects to the top of the capsule through the head of the docking cart. In the bait loading (home) position the top of the capsule is maintained in position by the upward pull of the recovery motor. The upward pull opens the spring loaded flaps over the bait windows to allow bait loading. The flattened sides of the nose cone of the capsule match the internal shape of the head section of the docking cart to ensure proper orientation for bait loading.

\subsection{Control Units}

The UW setter is controlled from two control units, the systems interface unit and the mode selection unit. The systems interface unit is mounted in the wheel house and operated by the skipper. It is used to set the target depth in relation to vessel forward speed (determines the amount of rope pay out from the recovery motor) and logs the number and GPS location of all hooks set on a fishing trip. The target depth is also logged. This information can be downloaded later via USB and used for issues relating to fishing strategy and to monitor compliance to the use of the UW setter. This form of compliance monitoring has the potential to remove the necessity for an on-board observer for issues related to seabird conservation. The mode selection unit is located on deck near the UW setter. It controls the mode of operation ("run" versus "maintenance") and has an emergency cut-off switch.

The UW setter concept is shown in Figure 1. The bait holding capsule and docking cart, and behaviour of the capsule underwater, are shown in Figure 2. Some of the components described above are shown in the Appendix.

To operate the UW setter a single baited hook is loaded into the capsule via the bait access window. The crew member operating the UW setter presses the start button on the audio beep timer and a second crew member clips the other end of the branch line to the mainline. The capsule and docking cart propel down the track at $~ 6$ $\mathrm{m} / \mathrm{s}$. The cart stops abruptly at the bottom of the track and is held there by the brake on the pull-down motor. The rapid descent down the track catapults the capsule underwater where it free-falls in the water column at $\sim 3$ 


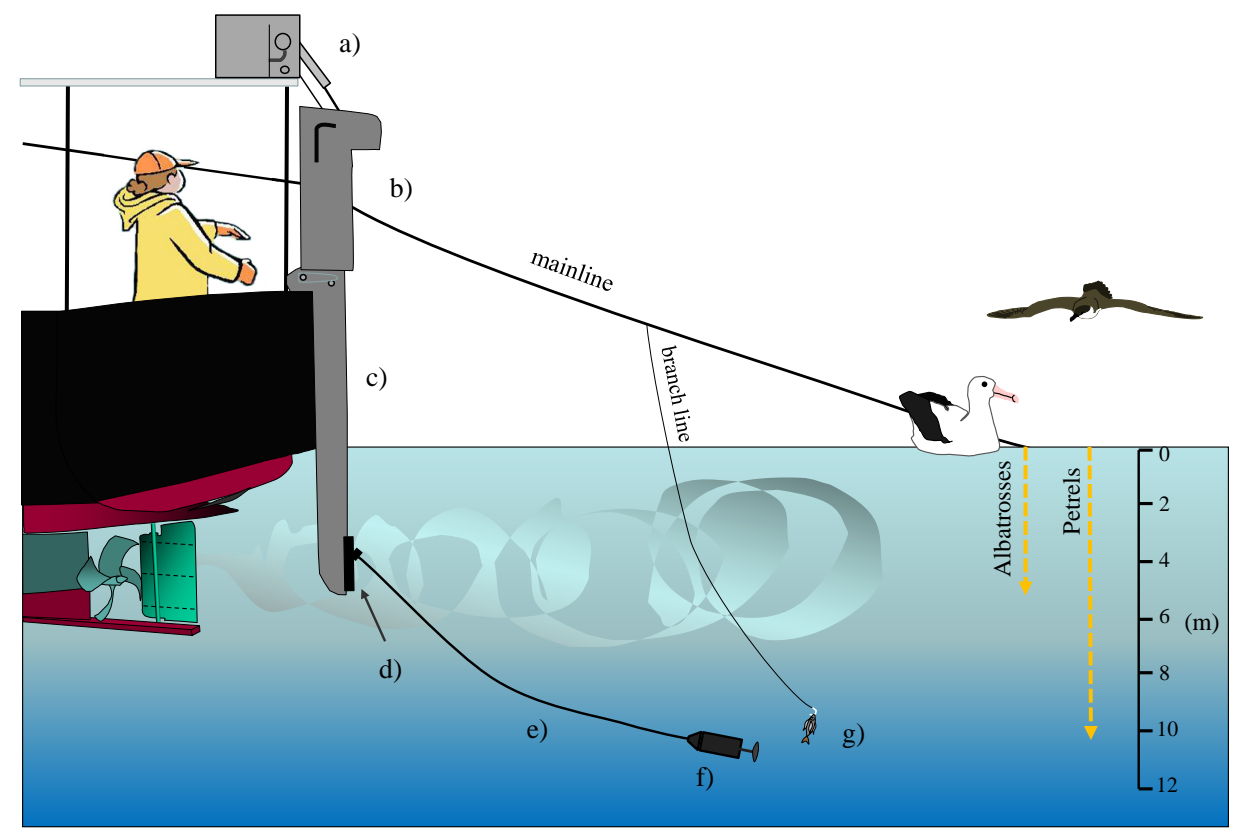

Figure 1. Schematic of the underwater bait setter showing the winch assembly (a); head section of the track assembly (b); the track attached to vessel transom (c); capsule docking cart (d); Spectra rope connecting the capsule to the recovery motor winch (e); capsule with bait door fully extended (f) and baited hook following release from the capsule (g). Not shown is the systems control unit (see text) which is located in the wheel house and operated by the skipper. Dive depths of the main seabird groups (see text) are indicated at right. The curved shapes above the capsule depict aerated water thrust from the propeller. Diagram not to scale.

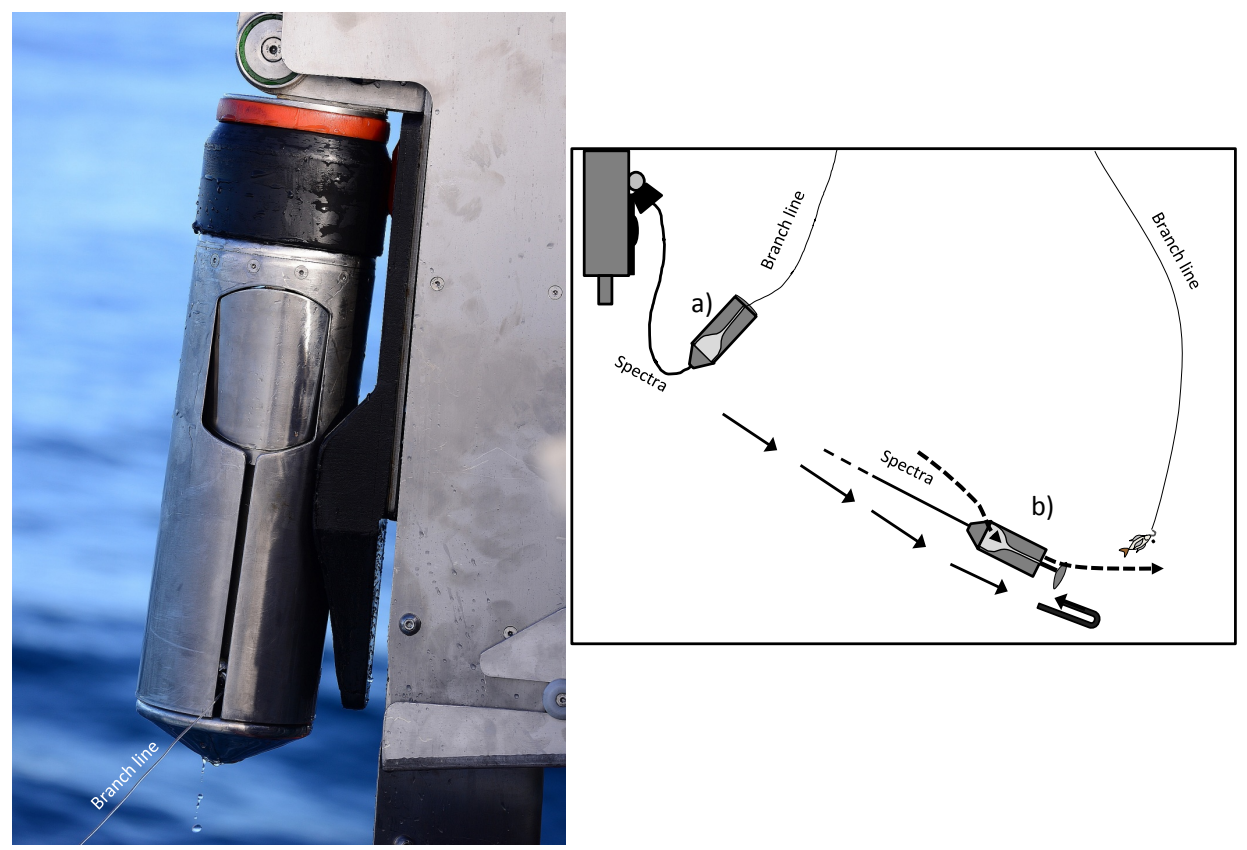

Figure 2. Left: The capsule and capsule docking cart in the home position in the head section of the track assembly. The bait loading window (with spring-loaded flaps) is shown at the top section and the bait exit door is shown at the bottom of the capsule in the closed position. The stainless steel capsule can be powder coated matt black in colour to reduce visibility underwater. Right: Stylised diagram of the behaviour of the capsule underwater. The capsule is catapulted free of the docking cart a), flips upside-down and free-falls to target depth. The recovery motor then engages, reversing the profile of the capsule and opening the spring-loaded flaps over the bait windows b). Water travels through the capsule (curving dashed line) opening the bait release door at the base of the capsule, releasing the baited hook. Diagram not to scale. 
$\mathrm{m} / \mathrm{s}$ to target depth. The target depth is pre-determined by the skipper. During the descent phase the recovery hydraulic motor pays out rope at a rate faster than vessel forward speed to eliminate dragging. Once target depth is reached the recovery motor engages (via the encoders and PLC) and the capsule ascends at $6 \mathrm{~m} / \mathrm{s}$. The rate of ascent slows when the capsule is about $1.5 \mathrm{~m}$ from the bottom of the track to allow the capsule to safely dock with the docking cart. The capsule and docking unit ascend the track to the home position. The cycle is repeated every 8 - 12 seconds, depending on depths targeted.

\section{Target Depth Standards}

The choice of target depths to prevent seabird mortality was based on the known dive depths and dive velocity of seabird species most vulnerable to mortality on longlines. In the Southern Hemisphere the commonest species killed in pelagic longline fisheries are black-browed albatrosses (Thalassarche melanophrys) and white-chinned petrels (Procellaria aequinoctialis). These species are abundant, aggressive bait takers and, in the case of whitechinned petrels, are active in the day and the night. The maximum dive depth for black-browed albatrosses is 4.5 m (mean: $2.5 \mathrm{~m}$; [11]). Therefore—and to err on the side of caution—baits released $\sim 6$ m underwater should prevent the mortality of this species of albatross.

White-chinned petrels are proficient divers, capable of reaching $16 \mathrm{~m}$ deep [12]. However, $<1 \%$ of dives attain this depth, the majority (95\%) being $\leq 6 \mathrm{~m}$ deep. Diving at $1.5 \mathrm{~m} / \mathrm{s}$ [12] a white-chinned petrel would take 6.7 seconds to reach $10 \mathrm{~m}$ deep. Baited hooks on conventionally weighted branch lines (60 g lead weight $3.5 \mathrm{~m}$ from the hook) released $\geq 6 \mathrm{~m}$ underwater averaged $0.41 \pm 0.01 \mathrm{~m} / \mathrm{s}$ (s.e. of the mean; $\mathrm{n}=87$ replicates; see General Methods, below). Therefore after 6.7 seconds elapsed time hooks released at $10 \mathrm{~m}$ would be $12.7 \mathrm{~m}$ deep-and sinking. This assumes dives occur the moment baits are released from the capsule, which is unlikely to be the case because baits released at $10 \mathrm{~m}$ depth would be only $10 \mathrm{~m}$ or $15 \mathrm{~m}$ astern (at 6 knots and 9 knots vessel speed, respectively, and a capsule sink rate of $3 \mathrm{~m} / \mathrm{s}$ ) and in the area of greatest turbulence from the propeller. The force of the water thrust from the propeller combined with the fact the water is heavily aerated must be a significant deterrent to diving. A bait release depth of $\sim 6 \mathrm{~m}$ should greatly minimise the mortality of white-chinned petrels and a release depth of $\sim 10 \mathrm{~m}$ should be sufficient to prevent mortality completely.

\section{Operational Trials}

While perfecting the design and performance of the above-water components of the UW setter required considerable research, development and operational testing over an eight year period (2007-2014), by far the most difficult of the challenges was perfecting the operation of the capsule. The capsule is catapulted underwater close to vessel sterns on the edge of the propeller turbulence zone. Water thrust from the propeller swirls chaotically with considerable force, making predictions about effects on the trajectory and operation of the capsule impossible. The evolution of the capsule involved sequential changes to the physical properties (size, structural strength, mass, weight balance), bait window flaps and bait release trap door and spring tensions in the bait windows and release door, with each iteration requiring extensive trialling at sea. A total of 12 capsules were built and tested to achieve the required standards. These were that the capsule must 1 ) cycle (time from release to recovery) at a rate practicable for fishing operations; 2) retain $100 \%$ of baits (no drop-outs) on the descent while descending at $6 \mathrm{~m} / \mathrm{s}$ on the track and $3 \mathrm{~m} / \mathrm{s}$ underwater; 3) release baits at target depths without drawing them up the water column (from hook-ups and/or suction); and 4) not affect the attachment of baits to hooks.

\subsection{General Methods and Results}

The research involved trials on several chartered longline fishing vessels operating from Mooloolaba $\left(26.68^{\circ} \mathrm{S}\right.$; $153.1^{\circ} \mathrm{W}$ ) Queensland, Australia. The most recent (and extensive) trials were conducted on the F/V Markarna, a $23.95 \mathrm{~m}$ steel displacement hull vessel operating in Australia's Eastern Tuna and Billfish Fishery. The final trials on the Markarna were conducted from 2-5 June 2014. The Markarna deploys $3.5 \mathrm{~mm}$ diameter monofilament mainline and $1.8 \mathrm{~mm}$ diameter monofilament branchlines (15 m long) with 14/0 circle hooks. Pilchard bait (Sardinus pilchardus) was used for all trials. Previous experience revealed pilchards hooked through the eye were more easily dislodged from hooks than squid (Illex argentines) hooked through the tail. This applied to both baits set by hand and baits set with the UW setter. Thus, successful outcomes with pilchard baits should apply, at minimum, to squid baits. In addition to assessing capsule sink rates and bait retention/release characteristics, the sink rates of baited hooks post-release from the capsule were determined to aid in defining the target 
depths mentioned above. Sink rates post-release were estimated using branch lines deployed on mainline from 10 to 20 seconds following release at $\geq 6 \mathrm{~m}$ deep. The various metrics of performance were estimated with Cefas G5 time-depth recorders (TDRs). These were deployed in the capsule alone, in both the capsule and on a baited hook inside the capsule, or on a baited hook inside the capsule alone, depending on the trial being conducted. The TDR deployment procedures were the same for all trials. The TDRs were programmed to record time and depth at 1 second or 0.1 second intervals, once again depending on the trial being conducted. The TDRs were time-synchronised with the computer to allow accurate estimations of water entry times and times to target depths. The analytical methods for the TDR data followed [13] and references therein. The methods specific to each operational trial, and the results of each trial, are presented below.

\subsection{Capsule Cycle Time and Depth Validations}

The capsule cycle times vary as a function of sink rate and recovery speed, and must be independent of the forward speed of the vessel. The sink rate is determined principally by the speed of capsule when catapulted into the water, and the physical properties of the capsule. The recovery time is determined by the physical properties of the capsule and capacity of the recovery motor. There is a tradeoff between cycle time and target depth - the deeper the depth the longer the cycle time. Hooks set by hand are typical deployed every 8 - 13 seconds. Given that bait loading takes $\leq 1$ second, the required cycle times for the $6 \mathrm{~m}$ and $10 \mathrm{~m}$ target depths were $7-12$ seconds. Target depths were assessed with paired TDRs inside the capsule and cycle times were recorded by the data logger in the systems interface unit. Vessel speeds were 6 knots, 7 knots, 8 knots and 9 knots, which covers the range of speeds adopted by vessels operating in pelagic longline fisheries in coastal States in the southern hemisphere. Target depths were $6 \mathrm{~m}, 8 \mathrm{~m}$ and $10 \mathrm{~m}$. The intermediate depth of $8 \mathrm{~m}$ was included as a potential option for industry. The results of the assessments are shown in Table 1.

\subsection{Bait Retention on the Descent}

The reliable delivery of baited hooks to target depths is critical to seabird conservation and was fundamental to our aim of developing a device that prevents seabird mortality without the need for other mitigation measures. A persistent problem with earlier versions of the capsule was baits dropping out via the bait window from inertia on the descent down the track, when the capsule flipped over underwater, and via the bait release door on descent to target depths. Examples of these malfunctions and of a normal bait release are shown in Figure 3.

Table 1. Summary of the relationship between vessel setting speed (over the water), bait release depth and cycle time. $\mathrm{N}=10$ for all speed $\mathrm{x}$ depth combinations.

\begin{tabular}{cccccccc}
\hline $\begin{array}{c}\text { Vessel speed } \times \text { depth } \\
\text { combinations }\end{array}$ & $\begin{array}{c}\text { Vessel } \\
\text { speed (knots) }\end{array}$ & $\begin{array}{c}\text { Nominal } \\
\text { depth }(\mathrm{m})\end{array}$ & \multicolumn{3}{c}{ Actual depth (m) } & \multicolumn{2}{c}{ Cycle times (sec) } \\
Mean-max & Min-max & Max-max & Mean & Range \\
\hline 1 & 6 & 6 & 5.4 & 4.9 & 5.8 & 7.4 & $7.2-7.6$ \\
3 & 7 & 6 & 5.7 & 5.5 & 5.8 & 6.9 & $6.8-7.1$ \\
4 & 8 & 6 & 5.7 & 5.2 & 6.2 & 7.4 & $7.3-7.7$ \\
5 & 9 & 6 & 5.7 & 5.0 & 6.2 & 8.9 & $8.0-9.2$ \\
6 & 6 & 8 & 6.8 & 6.5 & 7.1 & 9.4 & $9.2-9.8$ \\
7 & 7 & 8 & 7.6 & 7.1 & 8.0 & 8.6 & $8.4-8.9$ \\
8 & 8 & 8 & 7.5 & 5.5 & 8.1 & 9.3 & $9.1-9.5$ \\
9 & 9 & 8 & 7.4 & 6.7 & 8.0 & 11.4 & $11.0-11.8$ \\
10 & 6 & 10 & 8.9 & 8.2 & 9.4 & 11.7 & $11.3-12.0$ \\
11 & 7 & 10 & 9.1 & 8.7 & 9.6 & 10.3 & $9.9-10.7$ \\
12 & 8 & 10 & 8.9 & 7.3 & 9.7 & 11.2 & $10.6-11.6$ \\
& 9 & 10 & 9.7 & 9.1 & 10.3 & 15.2 & $14.7-15.6$ \\
\hline
\end{tabular}




\section{Time (sec)}

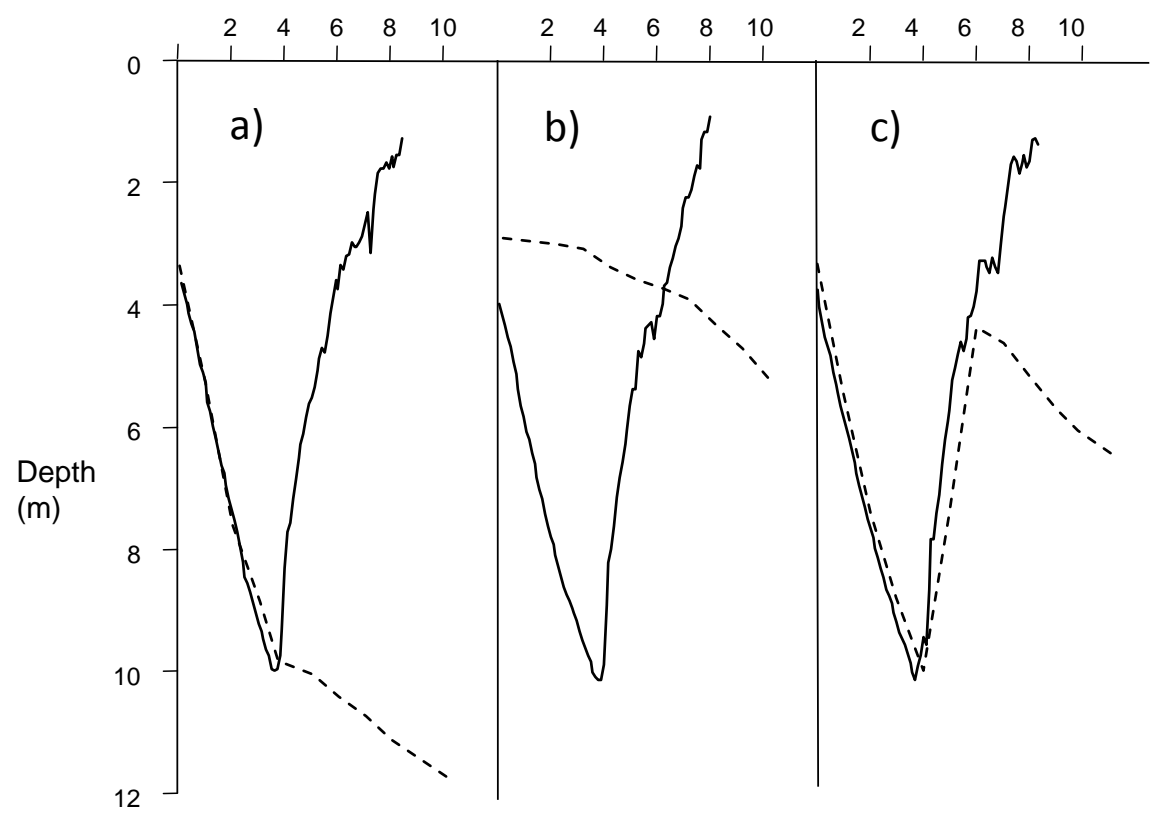

Figure 3. Examples of trajectories of the capsule (solid black line) and baited hook inside the capsule (dashed line; branch line tethered to vessel stern) showing a) descent of the capsule to target depth $(10 \mathrm{~m})$ and normal release of the baited hook and subsequent sinking; b) the baited hook dropping out of the capsule on the descent phase of the cycle; c) hook-up in the capsule then release on the ascent phase of the cycle. The lag from the surface to $\sim 4 \mathrm{~m}$ depth evident in the capsule descent profiles reflects the coarse (nearest second) recording of start times in the computer. The zigzags in the ascending limbs of the capsule profiles indicate contact with propeller turbulence near the vessel stern.

Trials with the final version of the capsule were conducted on the Markarna at setting speeds of 6 knots and 9 knots and nominal bait release depths of $6 \mathrm{~m}$ and $10 \mathrm{~m}$. A total of 606 deployments were made in the final trials. Bait retention was determined initially by comparison of sink profiles from a TDR inside the capsule with the profile of a TDR attached to the baited hook inside the capsule. The TDRs recorded time and depth at 0.1 second intervals and were time-co-ordinated to allow comparison of the profiles. Later, and based on the results from the paired TDRs, bait retention was assessed with a TDR on the baited hook inside the capsule (no dedicated TDR in the capsule itself). The trials were conducted by repeated deployment of a single $60 \mathrm{~m}$-long branch line tethered to a high speed reel on the vessel stern and by the repeated deployment of branch lines, each with a TDR, attached to the mainline as in normal fishing operations. The tethered branch line, equipped with a TDR at the hook, enabled much faster data gathering (and decision making regards subsequent problem solving efforts) than gear set on the mainline. The branch lines attached to the mainline were $20 \mathrm{~m}$ long so that $10 \mathrm{~m}$ depth could be consistently reached in big seas when wave action causes the vessel stern rise and fall. The results of the deployments are shown in Table 2.

\subsection{Bait Release at Target Depth}

With early models of the capsule baited hooks were frequently dragged up the water column from target depth during the capsule recovery phase, presumably from hooks snagging in the capsule, being slow to release and/or suction. Drag-backs of $\leq 0.05 \mathrm{~m}$ vertical distance were considered to be acceptable but drag-backs greater than this compromised the purpose of setting underwater. The incidence of drag-backs was assessed simultaneously with the assessment of bait retention during the descent (see above) by comparing the underwater profiles of a TDR on a baited hook in the capsule with those of a TDR attached to the inside of the capsule. Baited hooks were deployed on tethered branch lines and on individual branch lines attached to the mainline as described (Table 2). 
Table 2. Incidence of bait drop-outs from the capsule and bait drag-backs as a function of contrasting (fasters versus slowest) vessel setting speeds and bait release depths. Data from branch lines tethered to the vessel (see text) and set on mainline as in fishing operations are shown. $\mathrm{N}=606$ deployments.

\begin{tabular}{cccccc}
\hline Deployment method & Setting speed (kns) & Bait release depth (m) & Deployments (n) & Drop-outs (n) & Drag-backs (n) \\
\hline Tethered & 6 & 6 & 100 & 0 & 0 \\
Tethered & 6 & 10 & 100 & 0 & 0 \\
Tethered & 9 & 10 & 50 & 0 & 0 \\
Tethered & 9 & 10 & 50 & 0 & 0 \\
On mainline & 6 & 6 & 38 & 0 & 0 \\
On mainline & 6 & 10 & 115 & 0 & 0 \\
On mainline & 9 & 6 & 38 & 0 & 0 \\
On mainline & 9 & 10 & 115 & 0 & 0 \\
\hline
\end{tabular}

\subsection{Bait Retention on Hooks Post-Release from the Capsule}

If the quality of attachment of baits to hooks is compromised or the bait is damaged by the mechanical release underwater it could affect fish catch success. The quality of bait attachment on hooks following release from the capsule was compared with the quality of attachment of baits set by hand at the surface. A total of 260 branch lines comprising 130 set with the capsule and 130 set by hand, were deployed in alternating groups of 10 branch lines from the Markarna at 9 knots setting speed. All baits were of identical thaw status and condition. Baits deployed with the UW setter were released at $10 \mathrm{~m}$ depth. On completion of line setting the gear was hauled immediately (in reverse order to the setting order) to minimise bait damage or loss from causes other than method of setting (e.g., attacked by organisms in the sea) and bait attachment quality ranked using the following categories: 1) No damage—bait intact on hook; 2) Slight damage—guts protruding lightly; 3) Severe damage—body cavity exposed or partial skeleton); 4) Hook only—bait missing; 5) Head only—body bitten off and; 6) Shark or fin fish on hook. This method of comparison was complemented by recording the presence and absence of baits on hooks on the $60 \mathrm{~m}$ branch line tethered to the vessel during the bait retention/release trials described above. Presence or absence was determined by observing baits at the waters' surface following release from the capsule. Baits were dragged to the surface by the taut branch line against the combined forces of propeller turbulence and vessel forward speed (9 knots). Enduring this treatment and remaining intact on the hook was considered a good indication the attachments were not adversely affected by the mechanical release underwater.

With the UW setter versus surface setting comparison using mainline, the frequencies of classes 1 to 4 were compared across the two bait deployment methods using a loglinear model fitted as a generalized linear model [14] with Poisson response for number of baits and factors of bait damage class and deployment method (set by capsule or set by hand). Bait status classes of 5 and 6 were excluded because they cannot be used to directly infer the effect of setting method on bait retention. Class 4 indicates that the bait was torn off the hook and the null hypothesis in this case is that the cause applied equally to the two setting methods. The interaction between bait quality classes and setting method was not significant (chi square $=0.605$; d.f. $=3 ; P=0.90$ ) indicating that there was no detectable difference in the relative proportions of bait quality classes (Figure 4). Of the 650 branch lines tethered to the vessel for the bait retention/release trials, all baits were retained on hooks when released from the capsule and hauled to the surface through the propeller turbulence zone.

\section{Discussion}

\subsection{Duration of Research, Development and Testing Period}

The development and testing phases of the UW setter spanned nearly eight years and cost US \$1.1 million to complete. The total cost is an indication of the costs of commercial engineering and the charter of fishing vessel for operational trials. The length of time involved is not an accurate reflection of the time required to develop the UW setter to the point where it is ready for production fishing. In addition to the engineering developments that took years to finesse, the duration of the project reflects discontinuities in funding and access to fishing 


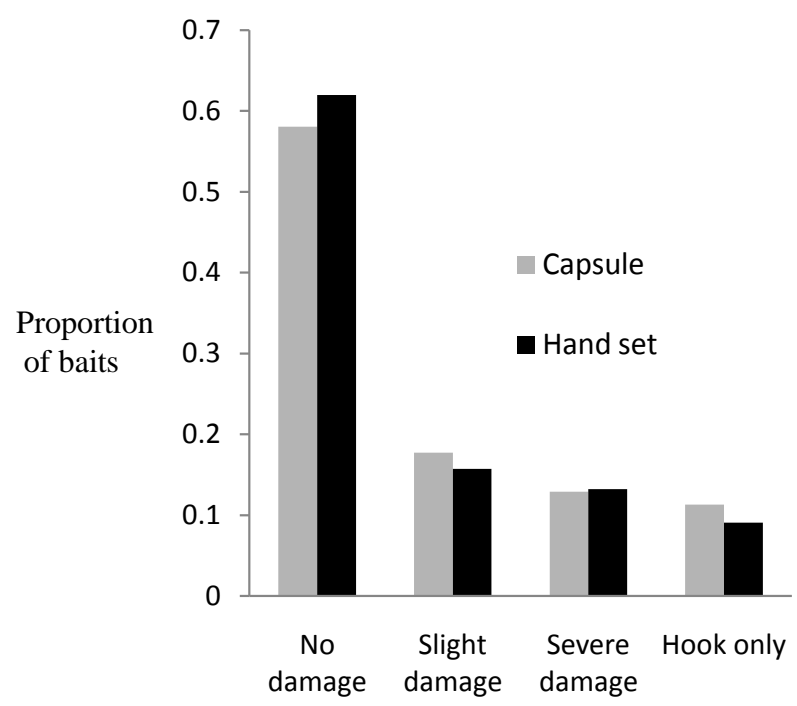

Figure 4. Proportion of baits in bait damage classes as a function of branch line setting method. See text for interpretation of damage classes. $\mathrm{N}=130$ deployments for each method.

vessels for sea trials. Commercial fisheries tend to be logistically complex and operate on schedules that are often unpredictable, and not easily compatible with research and development, especially with something as novel as the UW setter. Reliable access to a vessel "on demand" and lack of fiscal constraint would have shortened the development and testing period by several years.

\subsection{Cycle Times}

The standard established for the capsule cycle times to be practical for fishing operations were 7 seconds to $6 \mathrm{~m}$ depth and 12 seconds to $10 \mathrm{~m}$ depth. The vessel speed, capsule depth and cycle time validations shown in Table 1 reveal variation in both time and depth. The main source of variation was the rise and fall of the vessel stern with sea state. In general, the mean maximum depths in Table 1 are slightly less than nominal depth. Depth can be increased simply by paying out slightly more rope during the capsule descent phase, with a very minor effect on cycle time. Regards the cycle times, Table 1 reveals a small variation around the mean values, which is to be expected given the forces associated with a moving sea and a moving fishing vessel. Overall, the means are close approximations of our standard for the $6 \mathrm{~m}$ and $10 \mathrm{~m}$ depths, except for the $9 \mathrm{knots} / 10 \mathrm{~m}$ combination which was three seconds slower than required for fishing operations. The cycle time for this combination (and all the others) can be reduced by increasing the capacity of the recovery hydraulic motor from 50 cc to 80 cc, reducing the mass of the capsule (e.g., by judicious use of aluminium) or increasing the viscosity of the hydraulic oil (use of higher viscosity oil reduced the mean cycle time by three seconds, from 15.2 to 12.4 seconds). Our preference is to increase the capacity of the recovery hydraulic motor and reduce the mass of the capsule.

\subsection{Bait Retention and Release}

Ensuring all baits remained in the capsule to target depths, and released within $0.5 \mathrm{~m}$ of those depths, were the most onerous and time consuming (and expensive) problems to solve. Baited hooks are flushed from the spring loaded bait release door at the bottom of the capsule by water entering the capsule via the bait loading window in the top section of the capsule. The spring controlling the bait release door needed to be strong enough to keep the door close on the descent, but open fully at target depth due to the volume and force of the water entering the capsule via the bait loading windows. Further, the springs controlling the flaps on the bait release window had to be strong enough to maintain the flaps in the closed position for the descent but allow the flaps to spring open the instant the recovery motor engaged. The relative sizes of bait loading window and bait release door were key, as were the tensions of the springs controlling each. The "sweet spot" between the sizes of each of these openings and spring tensions had to be found with enough tolerance to enable the capsule to function properly when subjected to the range of sea conditions expected in production fishing. The perfect result from the 606 deploy- 
ments of tethered branch line and branch lines deployed on mainline shows that the final configuration of capsule had attained our performance standard.

\subsection{Bait Retention on Hooks}

As mentioned, retention of bait on hooks post-release from the capsule is crucial to the economics of fishing and uptake of UW setters by industry. Of the 650 deployments with a branch line tethered to the vessel all baits were retained on hooks following release underwater and hauled to the surface. With the 260 branch line deployed on mainline, there was no statistically detectible difference between setting methods. The degree of bait damage was consistent for both setting methods. These results support earlier findings that the retention of pilchard bait on hooks was mainly affected by the degree of thawing (fully thawed baits more easily dislodged), not the method of deployment. All in all there was no evidence the mechanical release underwater affected bait retention on hooks.

\subsection{Other Considerations}

As stated earlier, baits released about $6 \mathrm{~m}$ underwater should prevent the mortality of albatrosses and baits set to about $10 \mathrm{~m}$ underwater should prevent the mortality of diving species such as white-chinned petrels. Although this assessment is based on known seabird dive depths and is therefore logical, it is essential that actual mortality is determined, including any mortality of diving species associated with baits deployed within dive ranges (e.g., $6 \mathrm{~m}$ and $8 \mathrm{~m}$ depth). Setting to the shallower depths achieves faster cycle times, which will be attractive to some fishing operators. It is also important to determine any effects on fish catch, which is critical to the economics of fishing and adoption of UW setters by fishing operators. Evidence from the two proxy methods on bait retention post-release from the capsule shows no reason for concern, but this must be complemented with evidence from production fishing operations.

The UW setter was built for vessels operating in coastal States but can be adapted to other types of vessels including those operating on the high seas. These vessels are larger, set long lines at up to 11 knots vessel speed and deploy hooks at a faster rate-about every six seconds. Target depths can be reached with faster setting speeds by adding extra rope to the recovery motor winch, and cycle times can be reduced by the methods described previously. Other options include increasing slightly the interval between hooks and reducing vessel setting speeds. A further option is to deploy baits at shallower depths and increase the sink rate post-release from the capsule. Baited hooks on branch lines with $60 \mathrm{~g}$ lead weights $0.5 \mathrm{~m}$ from hooks released $\geq 6 \mathrm{~m}$ underwater averaged $0.59 \pm 0.01 \mathrm{~m} / \mathrm{s}(\mathrm{n}=36$ replicates) post-release, nearly $0.2 \mathrm{~m} / \mathrm{s}$ faster than conventionally weighted gear (60 g $3.5 \mathrm{~m}$ from hooks; $0.41 \pm 0.01 \mathrm{~m} / \mathrm{s} ; \mathrm{n}$ = 36; GR unpublished data). Baits released at, say, $6 \mathrm{~m}$ or $8 \mathrm{~m}$ depth (instead of $10 \mathrm{~m}$ ) and sinking at the faster rate would reduce the mean cycle times by 2 - 4 seconds (see Table 2) and should either prevent the mortality of diving species of seabirds or reduce it to very low levels.

\section{Conclusion}

Longline fishing for pelagic species is a threat to the existence of many albatross and petrel populations worldwide. The UW setter is a novel technology designed to prevent this form of mortality without the need for other seabird deterrent devices and practices. The UW setter deploys baited hooks underwater in a stainless steel capsule beneath seabird dive depths. The principal engineering challenges in developing the project involved ensuring consistent bait delivery to target depths, consistent bait release at target depths and that bait retention on hooks was not affected by the mechanical release underwater. Problems pertaining to these objectives have been solved and the device is now ready for market. The UW setter is modular in design and can be fitted to all types of vessel sterns.

\section{Acknowledgements}

The UW bait setter concept was developed by New Zealand fisher David Kellian and later by Australian fisher Tony Forster as a method of preventing seabird interactions with fishing gear. Dave and Tony identified Amerro Engineering as the company to bring the concept to fruition. The project was supported by generous grants from the David and Lucile Packard Foundation (USA), Quark Expeditions and Peregrine Adventures. We are especially grateful to Burr Heneman, Bernd Cordes and Kristine Ashfield from the Packard Foundation, and to Bill 
Davis, Alex Burridge, John Rodsted and David McGonigal from Quark Expeditions and Peregrine Adventures. We are also grateful to the passengers on tour ships operated by these companies for their generous support. We owe special thanks to Mr. Neil Roberts for donations from the proceeds of auction sales of his paintings and sculptures of Southern Ocean wildlife. The UW setter won the 2009 WWF Smart Gear competition and we gratefully acknowledge the financial assistance associated with that award. We thank Commercialisation Australia Pty Ltd for financial support in the latter years of the project. We are grateful to Garry Heilmann for use of the vessels Fortuna 2, Annandale, Sarah-J and Markarna for the research and to various skippers, especially Marty Wright and Peter Grennell, for their collaboration and ideas. We thank Barbara Wienecke for assistance with Figure 1 and Figure 2(b). Comments by Janice Molloy and Barry Baker improved a draft.

\section{References}

[1] Anderson, A., Small, C., Croxall, J., Dunn, E., Sullivan, B., Yates, O. and Black, A. (2011) Global Seabird Bycatch in Longline Fisheries. Endangered Species Research, 14, 91-106. http://dx.doi.org/10.3354/esr00347

[2] IUCN (2012) IUCN Red List of Threatened Species. www.iucn.redlist.org

[3] Croxall, J.P., Prince, P.A., Rothery, P. and Wood, A.G. (1998) Population Changes in Albatrosses at South Georgia. In: Robertson, G. and Gales, R., Eds., Albatross Biology and Conservation, Surrey Beatty \& Sons, Chipping Norton, 6983.

[4] Poncet, S., Robertson, G., Phillips, R.A., Lawton, K., Phalan, B., Trathan, P. and Croxall, J.P. (2006) Status and Distribution of Wandering, Black-Browed and Grey-Headed Albatrosses at South Georgia. Polar Biology, 29, $772-781$. http://dx.doi.org/10.1007/s00300-006-0114-9

[5] IUCN (2014) IUCN Red List of Threatened Species. www.iucn.redlist.org

[6] FAO (1999) International Plan of Action for Reducing Incidental Catch of Seabirds in Longline Fisheries. International Plan of Action for the Conservation and Management of Sharks. International Plan of Action for the Management of Fishing Capacity. FAO, Rome, 26.

[7] Lokkeborg, S. (2011) Best Practices to Mitigate Seabird Bycatch in Longline, Trawl and Gillnet Fisheries Efficiency and Practical Applicability. Marine Ecology Progress Series, 435, 285-303. http://dx.doi.org/10.3354/meps09227

[8] ACAP (2013) Report of the Seventh Meeting of the Advisory Committee. La Rochelle, 6-10 May 2013.

[9] Melvin, E.F., Guy, T.J. and Read, L.B. (2014) Best Practice Seabird Bycatch Mitigation for Pelagic Longline Fisheries Targeting Tuna and Related Species. Fisheries Research, 149, 5-18. http://dx.doi.org/10.1016/j.fishres.2013.07.012

[10] AAD (2006) Threat Abatement Plan for the Incidental Catch (or Bycatch) of Seabirds during Oceanic Fishing Operations. Australian Antarctic Division, Department of the Environment, Water, Heritage and the Arts, Hobart.

[11] Prince, P.A., Huin, N. and Weimerskirch, H. (1994) Diving Depths of Albatrosses. Antarctic Science, 6, 353-354. http://dx.doi.org/10.1017/S0954102094000532

[12] Rollinson, D.P., Dilley, B.J. and Ryan, P.G. (2014) Diving Behaviour of White-Chinned Petrels and Its Relevance for Mitigating Longline Bycatch. Polar Biology, 37, 1301-1308. http://dx.doi.org/10.1007/s00300-014-1521-y

[13] Robertson, G., Candy, S.G. and Hall, S. (2013) New Branch Line Weighting Regimes to Reduce the Risk of Seabird Mortality in Pelagic Longline Fisheries without Affecting Fish Catch. Aquatic Conservation: Marine and Freshwater Ecosystems, 23, 885-900. http://dx.doi.org/10.1002/aqc.2346

[14] McCullagh, P. and Nelder, J.A. (1989) Generalized Linear Models. 2nd Edition, Chapman and Hall, London. http://dx.doi.org/10.1007/978-1-4899-3242-6 


\section{Appendix}

Selected components of the UW bait setter. The figure below shows the UW setter mounted on the F/V Markarna. The modular construction enabled the UW setter to be mounted according to the layout of the vessel. The winch assembly unit is mounted on the poop deck (right) and connected by a chute (to guide the Spectra ropes from winches to the docking cart and capsule) to the head section of the track assembly (with capsule). The head section of the track assembly can be rotated inboard at the gunnel while transiting. The track can also be stored inboard while transiting.

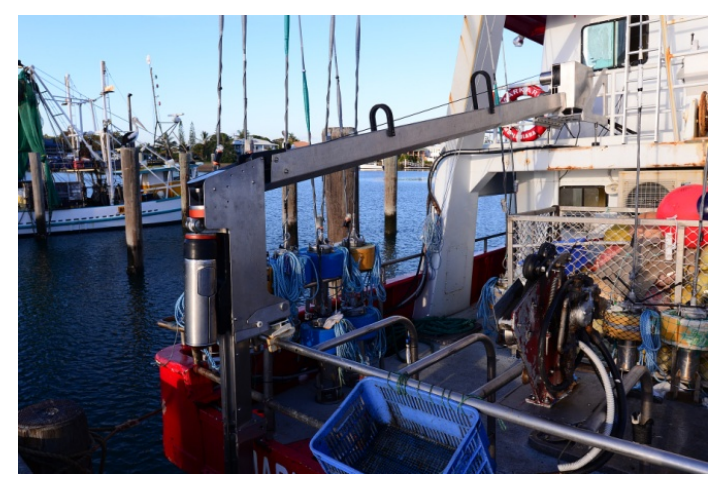

The figures below show the winch assembly unit (top), a portion of the head section of the track (bottom left) and the bottom section of the track (bottom right). The winch assembly is mounted on the vessel roof immediately above the head section of the track assembly, and is shown with weather-proof cover removed to reveal the pull-down and recovery hydraulic motors (left side), solenoids (lower right side) and electronic control box (top right). The head section of the track shows the capsule release magnetic switch and the bottom section of the track shows the water cushioning piston and spring (see text).
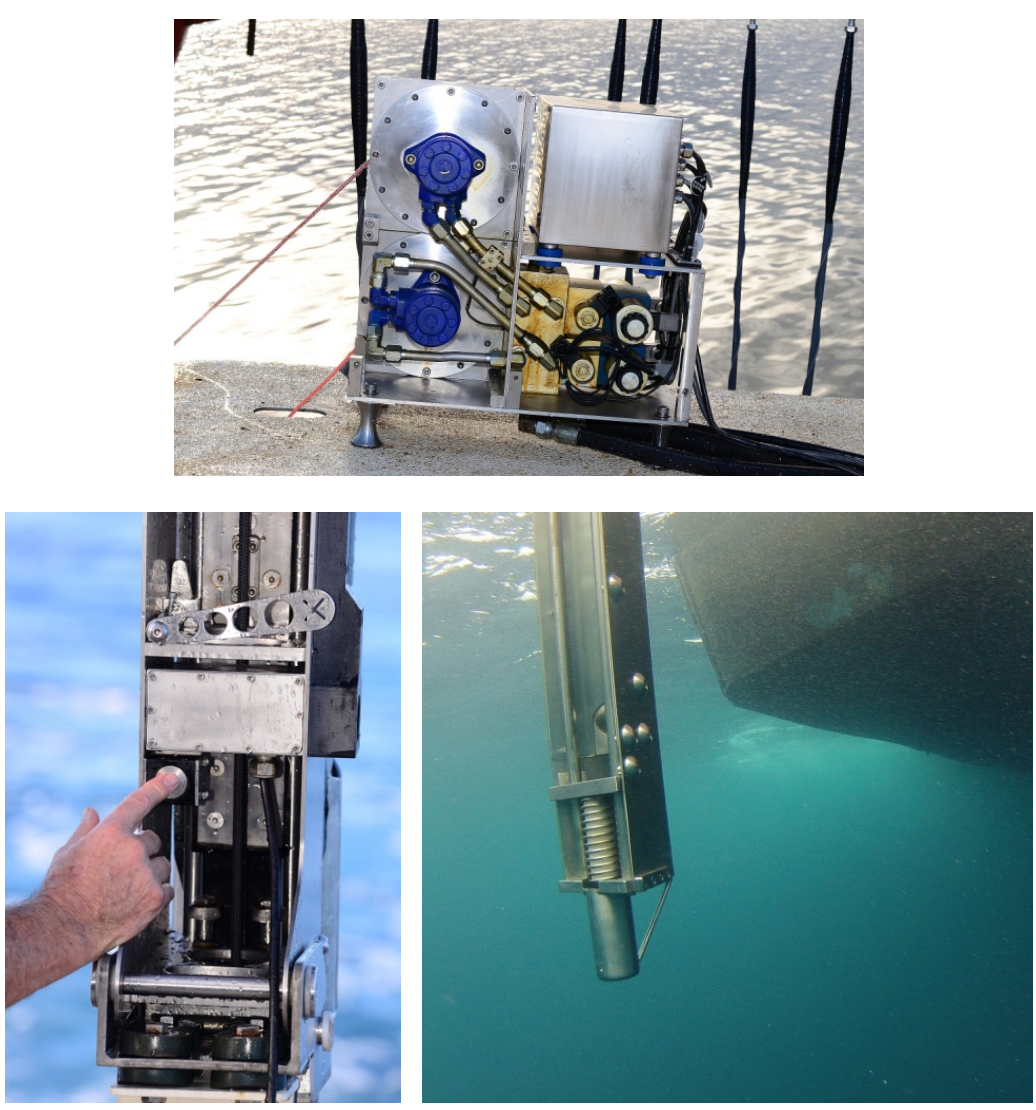
Scientific Research Publishing (SCIRP) is one of the largest Open Access journal publishers. It is currently publishing more than 200 open access, online, peer-reviewed journals covering a wide range of academic disciplines. SCIRP serves the worldwide academic communities and contributes to the progress and application of science with its publication.

Other selected journals from SCIRP are listed as below. Submit your manuscript to us via either submit@scirp.org or Online Submission Portal.
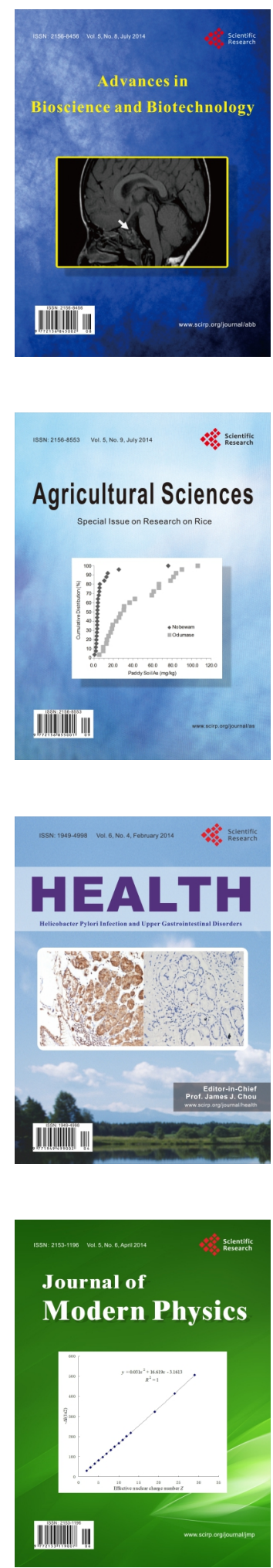
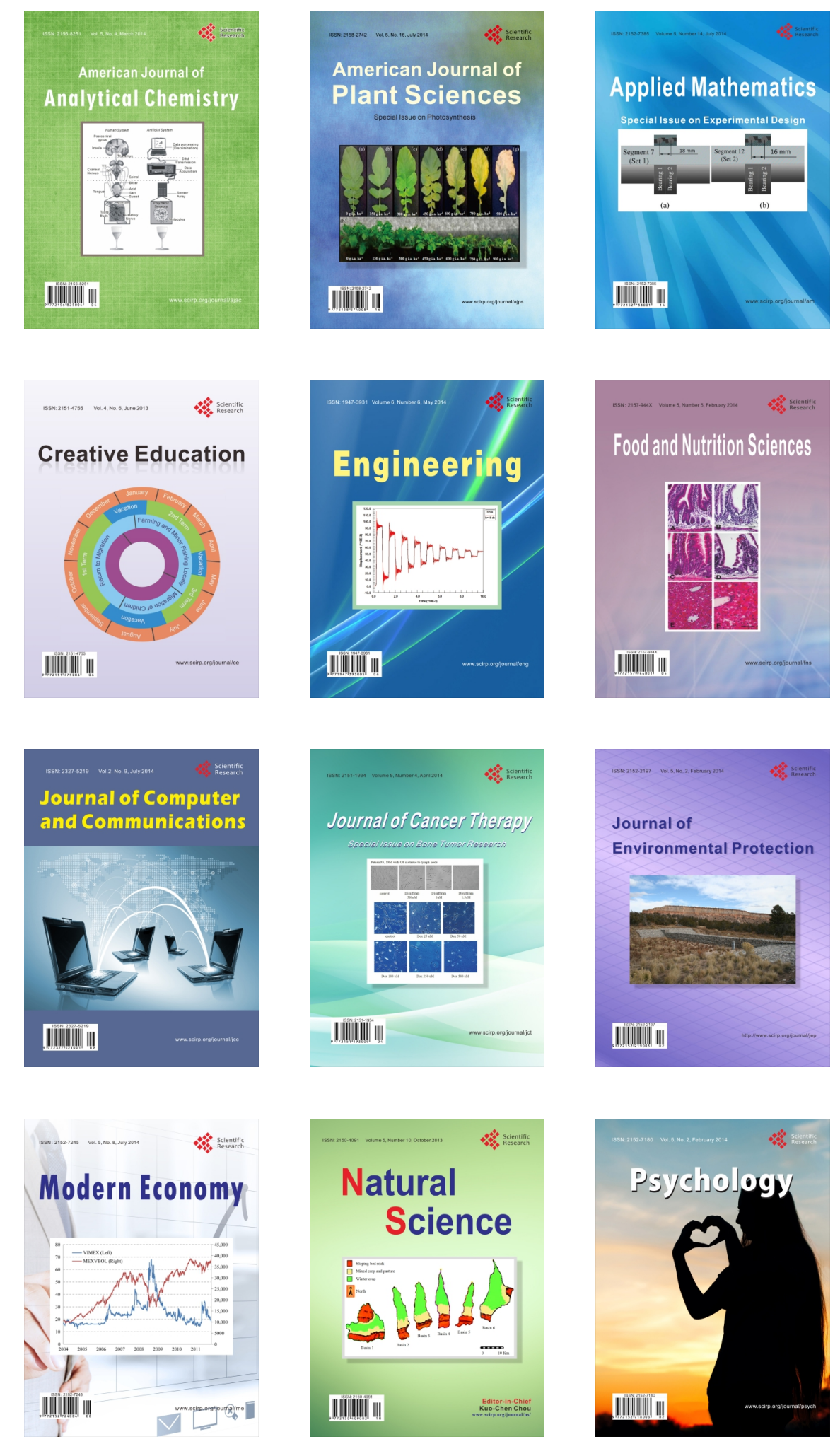